\title{
A EXPERIÊNCIA DA FAMÍLIA AO INTERAGIR COM O RECÉM- NASCIDO PREMATURO NO DOMICÍLIO
}

\author{
The family's experience when interacting with the premature \\ newborn at home
}

\author{
La experiencia de la familia al interactuar con el recién \\ nacido prematuro en el hogar
}

\author{
Suely Alves Fonseca Costa ${ }^{1}$ \\ Maria Magda Ferreira Gomes Balieiro ${ }^{4}$
}

Circéa Amalia Ribeiro²

Regina Issuzu Hirooka de Borba ${ }^{3}$

\section{RESUMO}

Estudo qualitativo que teve o objetivo de compreender como se dá a interação da família com o recém-nascido prematuro no domicílio, nas primeiras semanas após a alta hospitalar. O Interacionismo Simbólico foi o referencial teórico, e a Teoria Fundamentada nos Dados, o metodológico. Os dados foram coletados por observação participante e entrevistas com cinco famílias. A análise comparativa dos dados permitiu compreender que ter um filho, mesmo que prematuro, significa a realização de um sonho, cuja concretização faz com que a família vivencie dias de tristeza, angústia e dor decorrentes da prematuridade e hospitalização. Com a melhora clínica do bebê, ela se prepara para assumir seu cuidado no domicílio; acolhe-o com amor e carinho; vivencia mudanças no seu modo de ser, pensar e viver e sente-se recompensada. A compreensão dessa experiência oferece subsídios para repensar a assistência de enfermagem à família no seguimento do recém-nascido prematuro.

Palavras-chave: Enfermagem Neonatal. Prematuro. Enfermagem da Família.

\begin{abstract}
This qualitative study aimed at understanding how the family interacts with the premature newborn at home during the first weeks after discharge from hospital. The Theoretical and Methodological Frameworks used were the Symbolic Interactionism and the Grounded Theory, respectively. Data were collected by means of participant observation and interviews with 5 families. Data comparative analysis enabled us to understand that having a child, even if he/ she is premature, means a dream come true, whose realization causes the family to experience sadness, anguish and pain due to prematurity and hospitalization. With the baby's clinical improvement, the family gets ready to take over his/ her care at home, receives him/ her with love and care, experiences changes about their way to behave, think and live and feels rewarded. Understanding this experience provides subsides to rethink the nursing assistance given to the family during the follow-up of premature newborns.
\end{abstract}

Keywords: Meningomyelocele. Child Care. Disabled Children. Family.

\section{Resumen}

El presente estudio de tipo cualitativo tuvo por objetivo comprender la forma en que se presenta la interacción de la familia con el recién nacido prematuro atendido en el hogar, durante las primeras semanas después del alta hospitalaria. El referencial teórico de esta investigación fue el Interaccionismo Simbólico y metodológico en la Teoría Fundamentada de los Datos. Los datos fueron recolectados por medio de la observación participante y de entrevistas con cinco familias. El análisis comparativo de los datos permitió comprender que tener un hijo, aunque sea prematuro, significa la realización de un sueño, cuya concretización hace que la familia viva días de tristeza, angustia y dolor como consecuencia del nacimiento prematuro y de la hospitalización del bebé. Con la mejoría clínica del infante, la familia se prepara para asumir su cuidado en el hogar; lo acoge con amor y cariño; vivencia cambios en su modo de ser, pensar y vivir y se siente recompensada. La comprensión de esta experiencia ofrece contribuciones que sirven para replantear la asistencia que la enfermería ofrece a familia durante el cuidado del recién nacido prematuro.

Palabras-clave: Enfermería neonatal. Prematuro. Enfermería de la familia.

${ }^{1}$ Enfermeira. Especialista em Enfermagem Pediátrica. Enfermeira do Departamento de Pediatria da Irmandade de Misericórdia da Santa Casa de São Paulo. Supervisora de Estágio de Ensino Clínico da Disciplina Enfermagem em Saúde da Criança e Adolescente da Universidade Nove de Julho - UNINOVE. Brasil. E-mail: suelyfonsecacosta@ig.com.br, ${ }^{2}$ Enfermeira. Doutora em Enfermagem. Professor Associado do Departamento de Enfermagem da UNIFESP. Brasil.E-mail: caribeiro@unifesp.br, ${ }^{3}$ Enfermeira. Doutora em Enfermagem. Professor Adjunto do Departamento de Enfermagem da UNIFESP. Brasil. Email: rihborba@unifesp.br, ${ }^{4}$ Enfermeira. Doutora em Enfermagem. Professor Adjunto do Departamento de Enfermagem da UNIFESP. Brasil. E-mail: mmfgbalieiro@unifesp.br 
Família interagindo com o prematuro no domicílio Costa SAF, Ribeiro CA, Borba RIH, Balieiro MMFG

\section{INTRODUÇÃO}

A literatura tem enfatizado a impor tância da participação dos pais nas Unidades de Terapias Intensivas Neonatais (UTIN), para a promoção do crescimento e desenvolvimento físico e emocional do prematuro e estabelecimento do vínculo com a família. No advento da assistência neonatal, as mães eram bem-vindas nessas unidades, auxiliando nos cuidados do filho. Pierre Budim, considerado o primeiro perinatologista da era moderna, reconhece em seu livro "The Nursling", publicado em 1907, que as mães perdiam o interesse nos filhos quando não podiam cuidar. ${ }^{1}$

Com o avanço e a sofisticação da tecnologia, houve um afastamento da família deste cuidado, pois este se tornou cada vez mais complexo, exigindo conhecimento especializado, tanto para o manejo dos equipamentos como para o manuseio do próprio corpo do recém-nascido prematuro. Esta situação foi ainda reforçada pela crença de que a presença da família poderia aumentar o risco de infecção hospitalar e pela postura da equipe de saúde que passou a priorizar apenas o cuidado do neonato, relegando a assistência à sua família.

0 nascimento de um filho prematuro e a convivência com a internação em uma UTIN geram nos pais sentimentos de revolta, culpa, angústia, tristeza, medo, mas também esperança. ${ }^{2}$ Permeando os dias de hospitalização, esses sentimentos tornam-se menos árduos a partir do momento em que a família vai interagindo com equipe de enfermagem e começa a fazer planos para o futuro de seu filho. ${ }^{3}$

Estudos têm sido realizados sobre o impacto da participação das mães no cuidado ao recém-nascido prematuro e as condições para que se dê essa participação durante sua permanência no hospital. ${ }^{4-6}$

Um deles buscou conhecer o desejo materno de cuidar do bebê na UTIN, quais cuidados que gostariam de prestar e qual o auxílio requisitado para ser inserido no cuidado. As mães referiram vontade de prestar cuidados a seu filho, cuidados estes que, muitas vezes, são classificados como simples pela enfermagem, tais como: trocar as fraldas, dar banho, limpar os olhos, pôr roupas, segurar a cabeça, mexer na perna, cortar as unhas, limpar o ouvido e passar pomada. Para as mães, o fato de poder estar perto do bebê envolve sentimentos de bemestar, alívio, alegria e medo; elas relataram a necessidade de receber orientação, apoio e auxílio, para permanecerem um maior tempo na UTIN e, assim, concretizar seus desejos. ${ }^{4}$

0 autor de outro estudo enfatiza que para cuidar de família é necessário que o enfermeiro tenha sensibilidade, dedicação, conhecimento científico, capacidade para considerar e agir em relação ao outro. É preciso que a enfermagem atenda às necessidades e solicitações emergidas dos próprios pais e que estas necessidades só são percebidas quando os pais sentemse acolhidos e compreendidos. ${ }^{5}$

As ações da equipe de saúde realizadas em uma unidade neonatal, no sentido de favorecer o vínculo e apego mãe-filho em situação de prematuridade, estão assim descritas em uma publicação: as enfermeiras acompanham os pais na primeira visita, explicam a respeito dos equipamentos que cercam 0 recém-nascido, incentivam o contato pele-a-pele, o toque, a
Esc Anna Nery Rev Enferm 2009 out-dez; 13 (4): 741 -49

fala e ficam ao lado da mãe durante a visita. 0 médico pediatra informa a condição clínica do neonato, bem como fornece explicações sobre as alterações clínicas e equipamentos de alta complexidade. Nessa unidade, o acesso e a permanência dos pais junto aos bebês de risco são liberados, existe o programa de visitas dos avós e irmãos do prematuro, e os pais participam de um grupo de apoio, com outros pais que passam pela experiência de terem seus filhos prematuros em estado grave. ${ }^{6}$

As autoras desse mesmo artigo consideram que 0 relacionamento da equipe e da clientela vem melhorando intensamente, com maior acolhimento e vínculo, o que é constatado pelo retorno voluntário da mãe às unidades neonatais a fim de mostrar o filho para os profissionais que dele cuidaram durante a hospitalização. ${ }^{6}$

Como esses estudos referem-se às experiências e ações realizadas com a família durante a internação do recém-nascido prematuro, passamos a nos questionar em relação ao apoio que essas famílias necessitam receber no domicílio, daí terem surgido algumas indagações.

E após a alta? Como se dá a interação da família com seus filhos RNPT, depois de estas passarem dias e até meses convivendo com ele na UTIN? A família percebe-se preparada para cuidar de seu bebê no domicílio? Que apoio ela necessita para prestar esse cuidado? As relações que a família estabelece com o bebê no hospital influenciam no significado que seus membros atribuem às interações com o filho no domicílio?

Para responder a esses questionamentos, realizamos este estudo que teve como objetivo: compreender como se dá a interação da família com o recém-nascido prematuro no domićlio, nas primeiras semanas após a alta hospitalar.

\section{MÉTODO}

0 estudo foi qualitativo, o qual enfatiza a importância de se conhecer, entender e interpretar acuradamente a natureza de eventos e situações, quer sejam eles passados ou presentes. Esta abordagem tem relevância direta na prática de enfermagem, por proporcionar a compreensão dos acontecimentos que cercam a realidade do ser humano de uma forma mais abrangente, não fragmentada, na qual todas as partes têm relação com o todo, ou seja, há uma compreensão mais holística do sujeito.?

Como referencial teórico, adotamos o Interacionismo Simbólico (IS), uma perspectiva de análise das experiências humanas, que tem como foco de estudo a natureza da interação das pessoas com seu meio interno e externo, ou seja, o ser humano agindo em relação a si próprio, em relação aos outros e às coisas. ${ }^{8} 0$ referencial metodológico foi a Teoria Fundamentada nos Dados - TFD (Grounded Theory), que visa a descrever conceitos que emergem dos dados e interpreta a relação entre eles, permitindo a construção de modelos teóricos. Para tanto, a abstração é construída a partir da análise comparativa constante dos dados, sem a intenção de buscar evidências para a comprovação de hipóteses predeterminadas. ${ }^{9}$

0 local do estudo foi um hospital maternidade pública estadual, localizado na cidade de São Paulo, que é referência para atendimento a gestantes de alto risco, com a certificação 
de Hospital Amigo da Criança, desenvolvendo as práticas preconizadas por esta iniciativa.

Os sujeitos foram cinco famílias de recém-nascidos prematuros, que vivenciaram a internação do bebê na UTIN. Conforme preconizado pela TFD, o número de participantes foi determinado pelo critério de saturação teórica que ocorre quando há repetição e ausência de dados novos, assim como a crescente compreensão dos conceitos identificados. ${ }^{9}$

Os dados foram coletados em novembro de 2005 a julho de 2006. Antes de seu início, o projeto foi avaliado e aprovado pelos Comitês de Ética em Pesquisa, tanto da Universidade Federal de São Paulo como do local do estudo, sob os n 1502/ 05 e 0141/05, respectivamente, e os sujeitos participantes assinaram o Termo de Consentimento Livre e Esclarecido.

As estratégias utilizadas para a coleta dos dados foram: a observação participante e a entrevista, realizadas tanto no domicílio como no ambulatório de prematuros do hospital. Assim, foram observados e entrevistados os diferentes membros da família, tais como: avós, tios, irmãos e pais; embora a principal entrevistada tenha sido a mãe.

As entrevistas foram do tipo semiestruturadas e iniciaramse com a seguinte pergunta orientadora: Conte-me como está sendo a interação da família com o recém-nascido prematuro em casa? Durante seu transcorrer, foram formuladas outras questões com o intuito de explorar as verbalizações e aprofundar a compreensão dos conceitos emergidos.

Antes de iniciar as entrevistas, foi elaborado um genograma de cada uma das famílias que se constitui em gráficos convencionais genéticos e genealógicos da estrutura familiar. Esta estratégia, também utilizada por outros autores, teve 0 propósito de iniciar a interação com as famílias, facilitar a visualização da estrutura familiar dos recém-nascidos prematuros e das interações entre seus membros. ${ }^{10-11}$

A análise dos dados deu-se concomitante à sua coleta, conforme preconizado pela TFD, de acordo com as seguintes etapas: Codificação Aberta, que consiste em analisar cuidadosamente os dados e conceituá-los em forma de códigos; Categorização, o processo de agrupar os conceitos relacionados a um mesmo fenômeno; Codificação Teórica, que consiste em comparar exaustivamente as categorias entre si, de forma que elas sejam reorganizadas, agrupadas, reduzidas e densificadas até se alcançar a saturação teórica.

Embora o objetivo final desta abstração seja a construção de um modelo teórico representativo do fenômeno estudado, é importante ressaltar que a TFD configura-se em um processo de construção contínua, podendo ser interrompida em qualquer uma das etapas, sem incorrer em erro metodológico. ${ }^{12}$ Assim, este estudo não se desenvolveu até a construção do modelo teórico, sendo interrompido na fase da codificação teórica.

\section{RESULTADOS}

A análise dos dados permitiu a identificação da categoria conceitual "Acolhendo e cuidando do bebê com amor e carinho" (Figura 1), que retrata a experiência da interação da família com o recém-nascido prematuro no domicílio, expressa nas categorias que a compõem: "Realizando o sonho de ter um bebê", "Vivendo dias difíceis de hospitalização", "Acolhendo o

bebê com amor e carinho", "Assumindo o cuidado do bebê", "Mudando seu modo de ser, pensar e viver" e "Sentindo-se recompensada". Tais categorias serão a seguir apresentadas e ilustradas com exemplos extraídos das observações e entrevistas com os vários membros da família.

Figura 1: Diagrama - Acolhendo e cuidando do bebê com amor e carinho

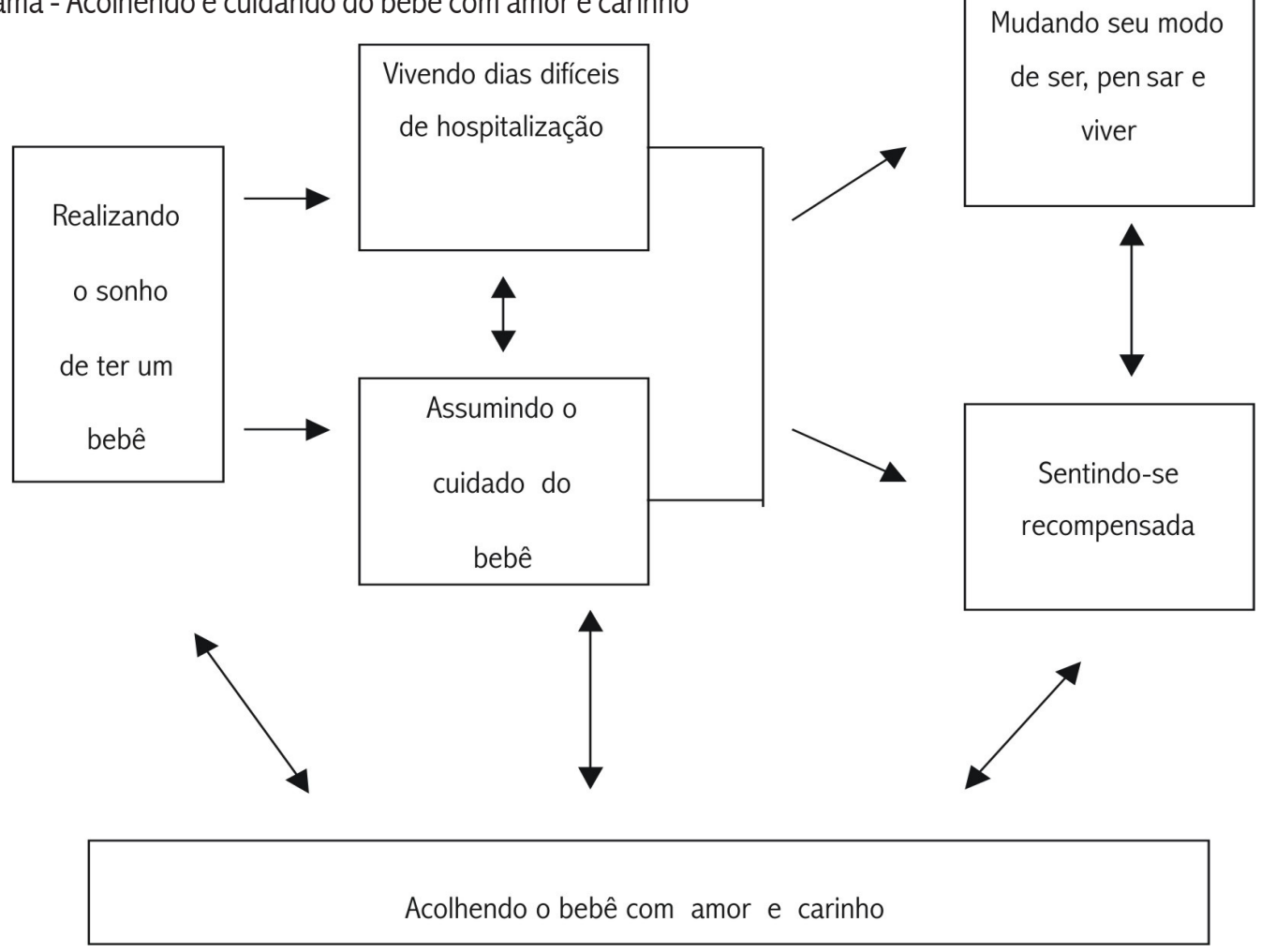


Família interagindo com o prematuro no domicílio Costa SAF, Ribeiro CA, Borba RIH, Balieiro MMFG

\section{- Realizando o sonho de ter um bebê}

Esta categoria, que se constitui na condição causal da experiência, revela que ter um filho, mesmo sendo prematuro, significa a realização de um sonho da família. Ainda que não tenha havido planejamento da gravidez, o bebê é aceito por todos os membros e renova a vida de seus integrantes, disseminando felicidade, sobretudo à mãe.

Ah! Eu estou feliz, eu nunca fui feliz assim de verdade com nada, mas com ele, eu estou muito feliz, só de olhar para a carinha dele. Eu não sei te explicar, é uma felicidade diferente [...] não foi planejado, mas quando eu descobri que estava grávida, eu aceitei, [...] eu estou muito feliz, porque eu sempre quis ter dois filhos homens, e agora eu tenho. (Entrevista com a mãe= EM)

No caso de haver uma doença da mãe, quando a família recebe a notícia da gravidez, seus membros ficam surpresos, amedrontados, porém felizes. Embora desejando o filho, seus integrantes não acreditavam que isto pudesse vir a acontecer, em razão de existir uma doença a superar. A partir de então, eles ficam unidos na expectativa do nascimento do filho e começam uma luta, a espera de um bebê saudável. Assim, 0 sonho de ter um bebê na família concretiza-se, embora em tempo e condições inesperadas.

[...] aía gente foi tentando, 10 anos que a gente se casou e não tinha nenhum, porque eu tinha pressão alta, tinha medo de engravidar. Mas, de repente, engravidei! Eu achava que não ia ter mais filho, de repente fiquei grávida dele. Todo mundo ficou feliz, começamos a lutar, para que ele viesse bem. (EM)

\section{- Vivendo dias difíceis de hospitalização}

Embora o nascimento do bebê seja a realização de um sonho, o fato de ele ser prematuro acarreta sua internação na UTIN, o que leva a família a viver dias de tristeza, angústia e medo, pois passa a conviver com um ambiente desconhecido a assustador. A mãe, interagindo com essas lembranças, traz esses dias vivos na memória e relembra o cenário da UTIN, como um local onde vivenciou muita dor e sofrimento, em decorrência da instabilidade clínica do bebê, do uso de aparelhos e das medidas terapêuticas empregadas pelos profissionais de saúde no tratamento do recém-nascido.

Um dos aspectos mais difíceis à família é o fato de interagir com a instabilidade do quadro clínico do bebê, que ora mostra uma piora importante. A lembrança dessa vivência continua determinando medo e insegurança, mesmo após a alta do filho.

Nossa! Foi horrivel para mim, porque eu não esperava um nenê prematuro. Eu não tinha a menor
Esc Anna Nery Rev Enferm 2009 out-dez; 13 (4): 741 -49

ideia como era uma UTI e ele por umas três vezes, ele parou de respirar. Ele estava no aparelho, ele fez duas apneias seguidas. Aí, eu tenho o maior medo de acontecer a mesma coisa. Eu tenho medo, quando eu vi ele, ele estava normal, aí ele foi ficando branquinho, foi ficando roxinho. Aí a médica teve que fazer adrenalina para ele voltar. Eu morro de medo de acontecer isso comigo aqui sozinha [...] eu não queria que ninguém passasse por isso, porque é uma péssima experiência. Acho que é a pior de todas [...] Ah, é muito triste! Eles são pequenininhos, ver eles lá com um monte de aparelhos, todos os dias. Eu vinha preocupada, sabe o dia que eu cheguei, eu tinha medo, porque ele já tinha sofrido; às vezes, está bem e, na mesma hora, já não está mais. (EM)

Além da instabilidade do bebê e do ambiente da UTIN, a existência das rotinas institucionais, como os horários rígidos e a restrição da visita aos familiares do recém-nascido, foi outro aspecto gerador de sofrimento à família, uma vez que impediu que os demais membros pudessem satisfazer o desejo de conhecer e interagir com o bebê.

[...] a família, todo mundo queria ver. Conhecer, né? Porque eles não podiam vir visitar, porque eles trabalham. Os horários não batem com os do serviço. (EM)

\section{- Acolhendo o bebê com amor e carinho}

Esta categoria revela como a família vivencia a chegada do bebê no domićlio. Neste contexto, todos se mostram carinhosos, abraçam, beijam e querem saber tudo sobre o bebê. É um momento que tem para a família um significado de intensa alegria e felicidade, e cada um de seus integrantes tem um jeito especial de demonstrar os seus sentimentos.

[...] está sendo maravilhoso! Criança é sempre bemvinda. (Entrevista com a avó=EV)

O pai entra no quarto, olha o bebê mamando e pergunta: de novo? Passa a mão no rostinho do bebê e fala: você está mamando de novo? Sai do quarto, entra de novo e fala: meu pretinho, [...] pega o álbum do bebê e mostra as fotos com ele dentro da incubadora, olha para o bebê deitado no carrinho e fala: olha que lindo!. (Nota de Observação=NO)

O tio beija o bebê, o pega no colo, mexe na mãozinha dele e fala: parece um bonequinho! A tia pega o bebê e beija. (NO)

Os irmãos mais velhos tratam-no como se fossem seus filhos. 
[...] tenho dois filhos casados, mas mesmo assim tratam bem (o irmão RN), como se fosse deles também. (EM)

Outro aspecto que revela o amor e o carinho do acolhimento do bebê pela família é o fato de ela querer saber tudo sobre ele. Quando ele chora, todos ficam perguntando o que ele tem e querem saber o porquê. Sempre que a mãe retorna do médico com a criança, ela precisa informar tudo à família.

[...] qualquer coisinha que ele tem, que é isso mãe? Por que ele chora? Todo mundo quer saber o que ele tem, o que se passa com ele. Quando vou ao médico, tem que dar o relatório todinho [...]. (EM)

\section{- Assumindo o cuidado do bebê}

Além de acolher o bebê com amor e carinho, assim que ele chega no domicílio, toda a família, incluindo os amigos, deseja compartilhar e envolver-se no cuidado do mesmo.

[... minha mãe (avó do bebê) ajuda, minha mãe dá banho também (EM.).

Eu só tenho uma amiga, só que agora ela está grávida, ela ajuda bastante. Hoje ela veio aqui [...]. (EM)

As crianças, assim como os adultos, também ficam alvoroçadas com a chegada do recém-nascido, querem ajudar os adultos, brincam com o bebê, querem pegar, balançar, trocar a fralda, dizendo que o bebê é deles. Mas a principal cuidadora é a mãe.

Mãe sentada na cama, dando de mamar para o bebê, enquanto o irmãozinho de 5 anos pula o tempo todo em cima dela. Pergunto a ele: de quem é esse nenê? Irmão responde: é meu! Dirige-se até o armário, pega um tênis e mostra. Pergunto: de quem é esse tênis? E ele responde: é do Vinícius (o bebê). (NO)

[...] eu estava escutando ela (irmã do bebê) gritar, mãe, mãe! [...] ela pegou o nenê de cima da cama, andou o quarto inteirinho com o nenê no colo. Assim, o que me dá mais trabalho, que é mais engraçado, é minha filha, a reação dela com ele, porque ela é pequenininha também, ela tem 1 ano e 5 meses e tudo ela quer fazer, ela quer trocar, ela quer pegar no colo, parecendo gente grande! (EM)

0 fato de as mães permanecerem com o bebê durante a hospitalização favorece que aprendem a cuidar dele. Muitas vezes, ficam mais de um mês na UTIN e quase duas semanas no Alojamento Canguru com seus bebês e, então, têm a oportunidade não só de observarem a equipe de enfermagem prestar o cuidado, como também aos poucos elas vão cuidando do bebê. Isto possibilita que elas desenvolvam a habilidade para pegar, com técnica adequada para não perder calor e peso, ou seja, aprendem com a enfermagem a cuidar. As mães aplicam este aprendizado no domicílio, cuidando do filho da mesma forma que lhes foi ensinado no hospital. Elas avaliam que se não tivessem tido a oportunidade desse aprendizado, não estariam conseguindo cuidar tão bem como estão.

[...] eu cuido direitinho, eu estou cuidando, né? Lá no hospital deu para aprender um pouco, sou mãe de primeira viagem [....]. Agora, eu estou cuidando bem. Se eu não tivesse ficado lá, eu não estaria cuidando tão bem, não. Lá eu vi as enfermeiras cuidando e tudo, acabei pegando o jeito também, [... No Canguru, eu fiquei quase duas semanas, mas ao todo fiquei mais de um mês. (EM)

[...] Eles me ensinaram: primeiro, tem que lavar um olhinho com algodão depois o outro. Enrolar no paninho, porque ele perde temperatura se ficar sem roupa, [...] continuo do mesmo jeito, banho dia sim e dia não, porque se não perde peso. 0 outro filho mais velho não prematuro não tinha essas coisas, eu dava banho de duas a três vezes ao dia. (EM)

Quando já teve outro filho prematuro, a experiência anterior em cuidar de um recém-nascido prematuro em casa faz com que cuidar desse bebê não seja novidade para a mãe, pois ela já está familiarizada com a situação, que é encarada com naturalidade.

[...] para mim é uma criança normal. É como se fosse o outro, grande ou pequeno, sei lá. Não tem muito que falar, porque se é o primeiro, ainda era aquela coisa, Né?Nossa! É pequenininho e tal, mas é o segundo! (EM)

Embora toda a família queira envolver-se no cuidado, a mãe, preocupando-se com a segurança do bebê, muitas vezes limita a participação dos familiares, sobretudo dos irmãos menores, impedindo-os de pegar a criança no colo. As mães ficam atentas ao bebê o tempo todo, pois a interação com as lembranças da convivência com sua instabilidade na UTIN faz com que elas se sintam inseguras em relação à vida do filho. Elas acreditam que pode acontecer algo de ruim com ele em casa; ficam com medo de dormir e não conseguir acordar quando o filho estiver se asfixiando com a coberta; sentem medo de não saber como agir na situação de o filho parar de respirar. Assim, vigiam o sono e a respiração do bebê constantemente, de dia e de noite.

Eu tenho medo na hora de dormir. Eu não consigo dormir à noite, porque eu acho que ele vaise asfixiar 
Família interagindo com o prematuro no domicílio Costa SAF, Ribeiro CA, Borba RIH, Balieiro MMFG

com a coberta. Eu acho que vai acontecer alguma coisa ruim, então, toda hora eu fico olhando. (EM)

[...] a gente fica até reprimindo às vezes, porque se não é de colo em colo. (EM)

[...] meu maior medo é de ele não respirar. Era de não saber cuidar dele, mas eu já perdi um pouco o trauma lá no Canguru, [...] meu medo era de não conseguir acordar à noite, mas eu estou conseguindo, eu tinha o sono pesado. (EM)

Por ser a principal cuidadora, muitas vezes a mãe acaba por ficar sobrecarregada. Esta sobrecarga verifica-se em razão da ausência de apoio consistente, inclusive da rede familiar, em virtude do trabalho da avó, da ausência do pai, da presença de outro filho pequeno, de seus familiares morarem distantes e de não ter condições financeiras de pagar alguém para ajudá-la. Assim, ela assume a maior parte e, algumas vezes, toda a responsabilidade do cuidado do bebê prematuro e dos outros filhos. Além disso, ela não consegue dormir direito à noite, pois, além de se preocupar em vigiar o sono do bebê, ela precisa amamentá-lo e fazê-lo arrotar, aproveitando para descansar um pouco, apenas, quando ele dorme à tarde.

Sou eu quem cuido, porque minha mãe trabalha, então é eu que cuido. Eu que dou de mamar. Nossa! Eu não durmo à noite, eu não durmo direito, eu tenho que fazer ele arrotar [...] Ah, eu não consigo dormir à noite; à tarde, eu dou umas cochiladinhas, quando ela dorme, né? Mas se ela não dorme, não dá pra deixar. (EM)

[...] eu cuido sozinha, eu não tenho condições de pagar alguém, e o pai dele rejeitou, [...] e o restante da familia mora em Minas. (EM)

\section{- Mudando seu modo de ser, pensar e viver}

A chegada do recém-nascido prematuro no domicílio determina, como consequência, mudanças no modo de ser, pensar e viver da família. A forma como a criança é recebida pelos irmãos é diferente da que a família esperava, e esta fica surpresa com a reação dos irmãos que não demonstram ter ciúmes, mesmo deixando de ser o filho caçula.

[...] sabe, pra ele foi ótimo. Foi ótimo mesmo, que ele sempre foi o irmão caçula. Eu achava que ele ia ter ciúmes, mas não teve, não! (EM)

A mãe deixa de ter vida própria para dedicar-se ao bebê e, por vezes, percebe que adquire mais responsabilidade, ficando mais atenciosa, inclusive, com os outros filhos.
Esc Anna Nery Rev Enferm 2009 out-dez; 13 (4): 741 -49

[...] mudou, agora eu sou mais responsável. Não dava muita atenção às coisas, eu não dava atenção para o meu filho. Eu não dava muita atenção para ele. Agora eu sou mais mãe, mais responsável. Antes eu tinha um filho só, eu não ligava, eu deixava ele no final de semana com o pai e ficava sossegada. (EM)

Embora tenha vivido dias difíceis de hospitalização, permeados pela insegurança e o medo de perder o bebê prematuro, com a sua melhora e a sua vinda para casa, a família atribui um novo significado à situação de prematuridade do bebê. Ela passa a idealizar um futuro cheio de realizações, espera que a criança cresça com saúde, estude, trabalhe e tenha uma vida social estável. A mãe, particularmente, deseja que o bebê conquiste tudo o que ela não pôde conquistar.

Mas eu espero que ele cresça com saúde, que ele vá para a escola, que não aconteça nada de ruim com ele, que ele estude. Tudo o que eu não pude ter, eu quero dar para os meus filhos. Eu quero muito que ele se forme e seja alguém. (EM)

\section{- Sentindo-se recompensada}

Outra consequência desta vivência é que, mesmo sentindose sobrecarregada com tanto trabalho, ao interagir com o recémnascido, a família sente-se recompensada. A mãe, especialmente, sente-se recompensada a cada instante que cuida, por tê-lo perto dela e refere vivenciar um prazer inexplicável em ver seu sorriso. Isso faz com que o trabalho de cuidar do filho prematuro seja atenuado.

[...] é trabalhoso, mas tem uma recompensa tão grande! Quando eu olho na carinha dele, ele dá um sorrisinho, é muito gostoso! É uma sensação! Não sei se é porque eu sou a mãe, é uma sensação tão gostosa, que nem dá para perceber que dá trabalho. (EM)

A dedicação, o carinho e o cuidado da mãe com o bebê são reconhecidos por outros membros da família. Eles ressaltam que a mãe sofre para cuidar da criança, que ela tem de ficar acordada a noite toda com o filho no colo, para ele não chorar, e que a sobrevivência dele deve-se à sua dedicação e cuidado.

[...] eu não saberia cuidar de recém-nascido prematuro, não! Se fosse meu ,já tinha morrido. Dá muito trabalho! Agora ele dorme, antes ele não dormia não. Ela (a mãe) sofreu, coitada! Precisa ser uma mãe muito cuidadosa. Ah, se você ver o choro dele, agora ele mama bem. Ela (a mãe) não dormia e nem ele(o bebê) dormia; chorava tanto! 
Quando ela punha ele no bercinho, ele acordava. Mas eu vou te contar, esse menino só sobreviveu porque a mãe dele é muito cuidadosa. (Entrevista com a bisavó= $E B$ )

\section{DISCUSSÃO}

A análise comparativa dos dados permitiu compreender que a interação estabelecida pela família com o recém-nascido prematuro no domićlio é um processo dinâmico, permeado de momentos felizes, porém trabalhosos e amedrontadores, que determinam sentimentos de realização, alegria, felicidade, ansiedade, medo e, também, demandam uma grande responsabilidade.

A família desenvolve com seu recém-nascido uma estrutura vincular desde antes da gestação, que começa a se concretizar no momento em que seus membros ficam sabendo da gravidez da mãe, quando a família passa a interagir com a percepção de estar realizando o sonho de ter um bebê, mesmo sabendo que este é um período crítico, especialmente se existe doença materna associada à gestação.

Este achado tem apoio na literatura ao enfatizar que a mulher, ao se perceber grávida, espera a evolução do período gestacional sem complicações. Romper este caminho significa desfazer os desejos, sonhos, aspirações ainda pulsantes na vida de cada gestante. ${ }^{13}$ Mas, quando o sonho de ter o bebê se concretiza em tempo e condições inesperadas como a prematuridade, a família passa a interagir com situações não idealizadas.

Embora não seja uma regra, a vivência da parentalidade, independente de ter sido ou não planejada, leva a família viver uma situação de crise, marcada de grandes desejos e expectativas, ${ }^{14}$ tornando-se mais desafiadora quando há um confronto do filho imaginário, esperado, com o nascimento prematuro $^{15}$, como vivenciaram as famílias deste estudo.

0 parto prematuro leva a família a viver dias de tristeza, angústia e dor interagindo com dias difíceis de hospitalização do filho na UTIN, cujo cenário é considerado pela família, especialmente pela mãe, como a pior lembrança de sua vida, pois o fato de conviver diariamente com a incerteza quanto à vida do bebê determina sentimentos de estresse, insegurança e medo. 0 enfrentamento dessa etapa da vida do bebê na UTIN, empreendendo os aparatos tecnológicos e medidas terapêuticas para salvar a vida do filho, marcam profundamente a família.

Este estudo que teve como objetivo desvelar o significado da experiência da família na UTIN, diante do nascimento de uma criança de alto risco, identificou que os pais demonstram ansiedade para acompanharem de perto o processo vivido pelo filho. Adicionalmente, a exclusão do cuidado fez com que se sentissem impotentes diante do sofrimento do filho, não lhes restando nada a fazer. Esta fase de instabilidade clínica do RNPT não permite garantias de seu prognóstico de vida, e isto leva os pais a um confronto com a terminalidade do filho, provocando-lhes angústia e medo. ${ }^{5}$
Logo que o bebê apresenta melhora de seu estado clínico, a família, representada especialmente pela mãe, começa a se preparar para estar assumindo o cuidado do bebê no domicílio. Este momento é caracterizado por um constante aprendizado, em virtude de proporcionar mais tranquilidade à experiência, visto que a mãe administra melhor seus sentimentos, quando conquista seu espaço de provedora do cuidado, pois o fato de cuidar do bebê faz com que ela se sinta mãe, como apontam outros estudos. ${ }^{4,15}$

Nesse aspecto, concordamos com os achados da literatura que enfatizam ser fundamental pensar em programas educacionais em unidades neonatais, envolvendo gradativamente os pais na assistência, considerando suas experiências e o contexto sociocultural, para que estes sejam verdadeiros parceiros no cuidado do filho. ${ }^{13}$

Após a alta, a chegada do bebê no domicílio faz com que a família se mobilize por ele, acolhendo-o com amor e carinho. Todos se mostram extremamente carinhosos, querem saber tudo sobre ele e ajudar a cuidá-lo. No entanto, a grande carga de cuidado fica com a mãe, que é reconhecida pela família como a pessoa mais indicada, o que determina seu sentimento de sobrecarga.

Ao mesmo tempo, após superar a convivência com os dias difíceis de hospitalização e vivenciar a vinda e o cuidado do bebê no domicílio, a família adquire uma nova forma de interagir com a situação de prematuridade. Ela passa a idealizar um futuro para esta criança, tendo esperança que cresça com saúde, estude, trabalhe e tenha uma vida social estável, e, assim, a família vai mudando seu modo de ser, pensar e viver. Estes momentos de interação com o bebê fazem também com que ela vá se sentindo recompensada, apesar de toda sobrecarga e preocupação que a vivência do cuidar de um recém-nascido prematuro acarreta.

Contudo, há estudos que apontam um número significativo de evasão do seguimento ambulatorial e um grande número de reinternações hospitalares de recém-nascidos prematuros egressos da UTIN. ${ }^{16}$

Este fato reforça a necessidade de a família ser apoiada não só durante a hospitalização, mas também após a alta do prematuro, pois, como enfatiza a literatura, todo o investimento tecnológico, científico, emocional e econômico que essas crianças receberam durante a internação hospitalar só será válido se elas tiverem direito ao acompanhamento de seu crescimento e desenvolvimento com profissionais capazes de envolver a família na assistência, ajudando-a a cuidar do filho no domicílio. ${ }^{16}$

Em um estudo que buscou identificar os cuidados domiciliares durante o primeiro mês após a alta hospitalar do recém-nascido de muito baixo peso, as autoras consideraram relevante o trabalho de enfermagem nas unidades neonatais e na rede básica de saúde, no sentido de estabelecer comunicações interinstitucionais, uma vez que as ações de enfermagem vão além do saber técnico e cientíico, como conhecimentos clínicos 
Família interagindo com o prematuro no domicílio Costa SAF, Ribeiro CA, Borba RIH, Balieiro MMFG

de higiene, de imunização, de alimentos, do efeito das medicações e do controle de retorno. Para elas, atender à família envolve disponibilidade e emotividade para compreender os vários aspectos vivenciados pela mãe, pela criança e pela família. $^{17}$

Neste sentido, o Programa Saúde da Família tem como propósito atender à família de forma integral e abordar a pessoa dentro de seu contexto familiar, incluindo suas necessidades afetivas, culturais, biológicas e espirituais e reconhecendo a

\section{CONSIDERACÕES FINAIS}

Ouvir as famílias deste estudo, com base nas premissas do IS e da TFD, constituiu-se em um rico aprendizado, pois permitiu a todos os seus integrantes expressarem seus sentimentos com relação ao nascimento do bebê prematuro, demonstrando amor, carinho e dedicação. No entanto, cada um deles tem uma forma diferente de interagir com o recém-nascido, e a mãe demonstrou ser ativa no papel de assumir os cuidados do filho, desde os primeiros momentos. Foi também revelada a importância da assistência de enfermagem à família, no sentido de prepará-la para o cuidado do bebê.

Observamos que 0 ambiente familiar não é apenas um espaço geográfico, mas sim um local onde existem pessoas que necessitam de apoio, atenção e cuidado. Sabemos que existem programas sociais, envolvendo famílias, que estão focados na saúde da criança e recém-nascidos normais. Entretanto, quando se trata de recém-nascido prematuro, há carência de protocolos para o acompanhamento sistemático no nível de atenção primária à saúde, deixando este serviço sob responsabilidade da instituição de origem.

Assim, esperamos que os resultados deste estudo ofereçam subsídios à equipe de saúde, com um novo olhar para a família

\section{REFERÊNCIAS}

1 Klaus M, Kennel JH. Atendimento para os pais de bebês prematuros ou doentes. In:Pais/ Bebê- a formação do apego. Porto Alegre (RS): Artes Médicas; 1993. p. 181.

2 Gaiva MAM, Ferriani MGC. Prematuridade: vivências de crianças e familiares. Acta Paul Enferm 2001 jan/abr; 14(1): 17-27.

3 Costa SAF, Santos MJA, Boas ASCV. Compreendendo a vivência da família com a internação do filho recém-nascido prematuro na UTI neonatal. Nurs 2007 dez; (115): 560-64.

4 Souza PT. Participação das mães nos cuidados ao recém-nascido pré-termo na unidade de terapia intensiva neonatal: sentimentos, desejos e necessidades [monografia]. São Paulo (SP): USP; 2000.

5 Gomes MMF. Nascimento de uma criança de alto risco: significado e vivência dos familiares. Acta Paul Enferm 1996; 9(n esp): 48-56.

6 Scochi CGS, Kokuday MLP, Riul MJS, Rossanez LSS, Fonseca LMM, LeiteAM. Incentivando o vínculo mãe-filho em situação de prematuridade- as intervenções de enfermagem no hospital das clínicas de Ribeirão Preto. Rev Latino-am Enfermagem 2003; 11(4): 539-43.
Esc Anna Nery Rev Enferm 2009 out-dez; 13 (4): 741 -49

família o principal cenário no qual ocorrem os conflitos que influenciam diretamente na saúde das pessoas. ${ }^{18}$

Concordamos que isto requer uma nova postura política e profissional das pessoas envolvidas na assistência do recémnascido prematuro, no sentido de saberem definir seu papel dentro do contexto hospitalar e social. Para tanto, é necessário criar recursos para adaptar os pais ao cuidado do filho, tanto no âmbito biológico como no afetivo, que são imprescindíveis para o seguimento ambulatorial do recém-nascido prematuro. ${ }^{17}$

do recém-nascido prematuro, revelando suas dificuldades, bem como as suas necessidades ainda durante a hospitalização e, especialmente, nas primeiras semanas após a saída do bebê do hospital.

Tais evidências levam-nos a refletir sobre a importância de implementarmos ações eficazes que apoiem a família que vivencia esta experiência, tais como: rever os horários de visitas da UTIN; oferecer apoio, para que os outros membros da família apropriem-se do cuidado do prematuro; auxiliar a família a pensar em estratégias a fim de que a sobrecarga da mãe seja atenuada; proporcionar o cuidado humanizado ao recémnascido prematuro durante sua permanência no hospital, assim como em seu seguimento após a alta hospitalar.

Ressaltamos que este é um estudo inicial e que, conforme os pressupostos da TFD, os conceitos emergidos podem ser mais aprofundados, para que o fenômeno estudado seja melhor compreendido, permitindo a construção de um modelo teórico representativo da experiência da família ao interagir com o recém-nascido prematuro no domicílio, após sua alta hospitalar.

7 Oh RIB. A utilização da abordagem qualitativa na pesquisa em enfermagem. In: Matheus MC, Fustinoni SM. Pesquisa qualitativa em enfermagem. São Paulo (SP): Livraria Médica Paulista; 2006. p. 24-7.

8 Ribeiro CA, Pettengil MAM. 0 interacionismo simbólico. In: Matheus MCC, Fustinoni SM. Pesquisa qualitativa em enfermagem. São Paulo (SP): Livraria Médica Paulista; 2006. p. 35-41.

9 Glaser BG, Strauss AL. The discovery of grounded theory. New York (USA): Aldine; 1967.

10.Wright LM, Leahey M. Enfermeiras e famílias: um guia para avaliação e intervenção na família. Tradução de Sílvia M. Spada. São Paulo (SP): Roca; 2002.

11 Christoffel MM, Pacheco STA, Reis CSC. Modelo Calgary de avaliação da família de recém-nascidos: estratégia pedagógica para alunos de enfermagem. Esc Anna Nery Rev Enferm 2008 mar; 12(1): 160-65.

12 Castro AS. Compreendendo o significado da vivência da cirurgia de postectomia para o pré-escolar [tese de doutorado]. São Paulo (SP): USP; 2001. 
Família interagindo com o prematuro no domicílio Costa SAF, Ribeiro CA, Borba RIH, Balieiro MMFG

13 Tronchim DMR. A experiência de tornarem-se pais de recémnascido prematuro [tese de doutorado]. São Paulo (SP): USP; 2003.

14 Cerveny CMO, Berthoud CME. Visitando a família ao longo do ciclo vital. São Paulo (SP): Casa do Psicólogo; 2002.

15 Wernet M. Experiência de tornar-se mãe na unidade de cuidados intensivos neonatal [tese de doutorado]. São Paulo (SP): USP; 2007.

16 Tronchin DMR, Tsunechiro MA. Prematuros de muito baixo peso: do nascimento ao primeiro ano de vida. Rev Gaucha Enferm 2007; 28 (1): 79-88.

17 Mello DF, Rocha SMM, Scochi CGS, Lima RAG. 0 cuidado da enfermagem no seguimento de crianças pré-termo e de baixo peso ao nascer. Rev Bras Cresc Desenvol Hum 2000; 10 (1): 49-60.

18 Ministério da Saúde (BR). Guia prático do Programa de Saúde da Família. Brasília (DF); 2001. 